\title{
Outcomes of resection for colorectal cancer hepatic metastases stratified by evolving eras of treatment
}

\author{
Kun-Ming Chan ${ }^{1 *}$, Jy-Ming Chiang ${ }^{2}$, Chen-Fang Lee ${ }^{1}$, Ming-Chin Yu', Wei-Chen Lee ${ }^{1}$, Jinn-Shiun Chen² and \\ Jeng-Yi Wang ${ }^{2}$
}

\begin{abstract}
Background and purpose: The outcomes and management of colorectal cancer (CRC) hepatic metastasis have undergone many evolutionary changes. In this study, we aimed to analyze the outcomes of patients with CRC hepatic metastasis in terms of the era of treatment.

Methods: We conducted a retrospective review of 279 patients who underwent liver resection (LR) for CRC hepatic metastases. The prognoses of patients treated pre-2003 (era 1) and post-2003 (era 2) were examined.

Results: Of the patients included in the study, 210 (75.3\%) had CRC recurrence after LR. There was a significant difference in the ratio of CRC recurrence between the 2 eras ( $82.0 \%$ in era 1 vs. $69.5 \%$ in era $2 ; p=0.008)$. Analysis of recurrence-free and overall survival rates also showed that the patient outcome was significantly better in the post-2003 era than in the pre-2003 era. Further analysis showed that a significantly higher percentage of patients in era 2 had received modern chemotherapeutic regimens including irinotecan and oxaliplatin, while patients in era 1 were mainly administered fluorouracil and leucovorin for adjuvant chemotherapy. Among patients with CRC recurrence, a significant ratio of those in era 2 underwent surgical resection for recurrent lesions, and these patients had a better survival curve than did patients without resection ( $34.1 \%$ vs. $2.2 \%$ for 5 -year survival; $p<0.0001$ ).

Conclusion: The incidence of CRC recurrence after LR for hepatic metastasis remains very high. However, the management and outcomes of patients with CRC hepatic metastasis have greatly improved with time, suggesting that the current use of aggressive multimodality treatments including surgical resection combined with modern chemotherapeutic regimens effectively prolongs the life expectancy of these patients.
\end{abstract}

Keywords: colorectal cancer, hepatic metastasis, liver resection, recurrent patterns, evolving eras

\section{Background}

Hepatic metastasis is the most common form of distant spread of primary colorectal cancer (CRC) and occurs in over $50 \%$ of patients with metastases. Aggressive liver resection (LR), which provides the only curative treatment, is believed to have improved the long-term outcome of these patients [1-3]. Recently published studies have shown that these patients have variable 5 -year survival rates ranging from $36 \%$ to $58 \%$ [4-8]. However, despite the excellent results of aggressive treatment for

\footnotetext{
* Correspondence: chankunming@adm.cgmh.org.tw

'Department of General Surgery, Chang Gung Memorial Hospital at Linkou,

Chang Gung University College of Medicine, Taoyuan, Taiwan Full list of author information is available at the end of the article
}

metastatic CRC, numerous patients still develop recurrence after LR for metastatic tumors.

Although the prognostic factors and scoring systems that determine patient outcomes after LR are well established,[4,9-11] most of the information regarding LR for metastatic CRC is from Western countries. However, CRC has become a common gastrointestinal malignancy and subsequently ranked as a leading cancerous disease in Taiwan and other East Asian countries during recent years. Thus, we gathered data and retrospectively reviewed our experience of LR for patients with hepatic metastasis from CRC. Additionally, since the treatment of metastatic CRC has changed greatly over the last decade, the patient
C Biomed Central 
cohort was grouped according to the timeframe of treatment to evaluate the evolution of outcome over the years.

\section{Materials and methods Patients}

This study included 279 patients with CRC hepatic metastasis who underwent LR with curative intent between July 1988 and December 2008 at Chang Gung Memorial Hospital Linkou Medical Center (Taoyuan, Taiwan). The data in the medical records of these patients were retrospectively reviewed and analyzed for clinical characteristics, surgical management, and outcome upon approval of the institutional review board. Hepatic metastasis of CRC was confirmed for all patients by histological examination of specimens derived from LR. There were 177 men and 102 women, and their median age at the time of LR was 61 years (range, 21-88 years). The patient cohort was divided into 2 subgroups: the first 15-year period was defined as pre-2003; era $1, n=128$ ), and the later 5 -year period was defined as post-2003; era 2, $n=151$ ). The clinicopathologic features and outcomes of patients were compared between the 2 groups.

\section{LR for CRC hepatic metastases}

Before surgery, all patients were thoroughly evaluated with appropriate imaging studies, including computed tomography (CT) of the abdominal and pelvic areas, chest roentgenography, and/or chest $\mathrm{CT}$, to determine the clinical status of the CRC and hepatic metastasis. Positron emission tomography (PET) or PET/CT was not routinely performed, but were done for patients who had undergone equivocal conventional imaging studies to confirm advanced disease and, occasionally, to identify potentially resectable lesions. Resectability with curative intent required complete resection of all hepatic metastatic lesions and preservation of a sufficient volume of remnant liver. In particular, a patient with concurrent unresectable extrahepatic metastases was considered unsuitable for LR. LR was performed using either the surgical clamp-crush technique or the Cavitron Ultrasonic Surgical Aspirator (CUSA; Valleylab, Inc., Boulder, CO, USA). Inflow vascular control was not routinely applied during the transection of liver parenchyma. The extent of LR was defined according to Couinaud's classification of liver segments.

\section{Postoperative follow-up}

After LR, patients were followed up and monitored for tumor recurrence by physical examination, measuring the serum carcinoembryonic antigen (CEA) levels, and conducting abdominal ultrasonography 1 month after surgery, and every 3 months thereafter. CT and/or magnetic resonance imaging of the chest, abdomen, and pelvis were performed at yearly intervals or whenever cancer recurrence was suspected. A PET or PET/CT scan was occasionally arranged for patients who underwent equivocal conventional imaging studies and experienced unexplained elevation of serum CEA levels after 2003. Perioperative chemotherapy mainly depended on tumor characteristics indicating aggressive disease, availability of chemotherapeutic regimens, patient's physical condition, and affordability of the chemotherapy drugs. Usually, postoperative adjuvant chemotherapy was recommended for all patients, unless a patient was unwilling to receive chemotherapy or a patient's physical status was unsuitable for chemotherapy administration. The chemotherapeutic options were mostly fluorouracil and leucovorin before 2003 and a combination of new options, including irinotecan, oxaliplatin, capecitabine, bevacizumab, and cetuximab, after 2003. Pyrimidine analogue capsules were prescribed for patients who had not received intravenous chemotherapeutic regimens. CRC recurrence was defined as the presence of a lesion that was histologically proven from either biopsy or surgical resection or the presence of a lesion that was detected by cross-sectional imaging studies and/or concurrent with an elevation in serum CEA level. Intrahepatic recurrence (IHR) was defined as tumor recurrence initially detected in the liver and no additional extrahepatic lesions detected within the following 3 months. Systemic recurrence (SR) was defined as initial recurrence found outside the liver or both intra- and extrahepatic lesions simultaneously discovered or sequentially detected within a 3-month period. Overall, 6 patients were lost during the follow-up period, and the median follow-up period for these patients was 25.5 months (range, 4.0-240.1 months). The remaining patients were followed up until death or the end of this study.

\section{Statistical analysis}

Statistical analyses were carried out using the statistical software SPSS 13.0 (SPSS, Inc., Chicago, IL, USA) for Windows. The outcome measures included recurrencefree survival (RFS) and overall survival (OS). RFS was calculated from the date of LR to the date of detected recurrence. The status of CRC recurrence was recorded at the date of last follow-up for patients who were lost to follow-up or died of other diseases, or the end of this study. OS was measured from the date of LR to the date of death. Categorical clinicopathologic features were assessed with chi-square or Fisher's exact test. The Cox regression proportional hazards model was used to identify factors influencing RFS, and all significant prognostic factors determined in univariate analysis were then selected for multivariate analysis. The survival curves were constructed using the Kaplan-Meier method, and the curves were compared using the log-rank test. A $p$ value of $<0.05$ was defined as statistically significant. 


\section{Results}

\section{Demographics and clinicopathologic characteristics}

The median follow-up period for the study patients was 27.2 months (range, 0.8-269.2 months). During followup, 210 patients $(75.3 \%)$ developed CRC recurrence, and the median time of recurrence was 9.0 months (range, 1.1-129.8 months). Overall, at the end of this study, 191 patients (68.5\%) had died, 26 (9.3\%) were alive with CRC, and $62(22.2 \%)$ were alive without evidence of CRC. Table 1 summarizes and compares the clinicopathologic characteristics of the patients in era 1 and era 2 . There were significant differences in the age distribution, tumor number, CRC recurrence, and perioperative chemotherapy between the 2 groups. Patients in era 2 were older, had a higher percentage of multiple hepatic metastases (44.4\% in era $2 v s .24 .2 \%$ in era $1 ; p<0.001$ ), had a lower rate of CRC recurrence (69.5\% vs. $82.0 \% ; p=0.008)$, and received perioperative chemotherapeutic regimens different from those in era $1(p<0.0001)$. Further detailed analysis regarding chemotherapies showed that a higher percentage of patients in era 2 received fluorouracil and leucovorin combined with irinotecan and oxaliplatin, while patients of era 1 were mainly administered fluorouracil and leucovorin for adjuvant chemotherapy. Notably, $8(5.3 \%)$ patients who were initially considered unsuitable for LR became eligible for surgical resection after chemotherapy in era 2 . There was no significant difference in the surgical mortality between the 2 groups.

Table 1 Clinicopathological characteristics of patients undergoing LR for hepatic metastasis from CRC in different eras.

\begin{tabular}{|c|c|c|c|}
\hline Characteristics & $\begin{array}{c}\text { Era } 1 \\
n=128(\%)\end{array}$ & $\begin{array}{c}\text { Era 2 } \\
n=151(\%)\end{array}$ & $p$ value \\
\hline Age in years, median (range) & $59(21-81)$ & $63(29-88)$ & 0.009 \\
\hline Gender & & & 0.194 \\
\hline Male & $76(59.4)$ & $101(66.9)$ & \\
\hline Female & $52(40.6)$ & $50(33.1)$ & \\
\hline Primary tumor location & & & 0.112 \\
\hline Colon & $65(50.8)$ & $91(60.3)$ & \\
\hline Rectum & $63(49.2)$ & $60(39.7)$ & \\
\hline \multicolumn{4}{|l|}{ Liver metastasis } \\
\hline CEA (mg/dL), median (range) & $15.5(0.5-7025)$ & $12.4(0.8-4280)$ & 0.743 \\
\hline Metastatic type & & & 0.471 \\
\hline Synchronous & $85(66.4)$ & $94(62.3)$ & \\
\hline Metachronous & $43(33.6)$ & $57(37.7)$ & \\
\hline Tumor number & & & $<0.0001$ \\
\hline Solitary & $97(75.8)$ & $84(55.6)$ & \\
\hline Multiple & $31(24.2)$ & $67(44.4)$ & \\
\hline Maximum tumor size $(\mathrm{cm})$ & & & 0.331 \\
\hline$<5$ & $108(85.7)$ & $122(81.3)$ & \\
\hline$\geq 5$ & $20(14.3)$ & $29(18.7)$ & \\
\hline Extent of liver resection & & & 0.209 \\
\hline$<3$ segments & $88(68.8)$ & $114(75.5)$ & \\
\hline$\geq 3$ segments & $40(31.2)$ & $37(24.5)$ & \\
\hline Perioperative chemotherapy & & & $<0.0001$ \\
\hline FU or with LV & $69(54.0)$ & $8(5.3)$ & \\
\hline FU/LV/oxaliplatin & $9(7.0)$ & $36(23.8)$ & \\
\hline FU/LV/irinotecan & $9(7.0)$ & $67(44.4)$ & \\
\hline Other regimens & $22(17.2)$ & $30(19.9)$ & \\
\hline No & $19(14.8)$ & $10(6.6)$ & \\
\hline CRC recurrence & & & 0.008 \\
\hline IHR & $57(44.5)$ & $43(28.4)$ & \\
\hline SR & $48(37.5)$ & $62(41.1)$ & \\
\hline No & $23(18.0)$ & $46(30.5)$ & \\
\hline Resection of CRC recurrence & $10(9.5)^{*}$ & $31(29.5)^{*}$ & 0.003 \\
\hline Surgical mortality & $2(1.6)$ & $2(1.3)$ & 1.000 \\
\hline
\end{tabular}

LR, liver resection; CRC, colorectal cancer; CEA, carcinoembryonic antigen; FU, fluorouracil; LV, leucovorin; IHR, intrahepatic recurrence; SR, systemic recurrence; * represents percentage among CRC recurrence. 


\section{Prognostic factors affecting CRC recurrence}

Among the patients who developed CRC recurrence, 100 (47.6\%) had IHR and 110 (52.4\%) had SR according to the classification of recurrence patterns. In era 1, 57 (44.5\%) patients had IHR and 48 (37.5\%) patients had SR, while in era 2, $43(28.4 \%)$ patients had IHR and $62(41.1 \%)$ patients had SR. Table 2 provides an analysis of the risk factors for $\mathrm{CRC}$ recurrence according to the different eras. Univariate analysis showed that the type of hepatic metastases and number of metastatic tumors were significant factors in era 1. Subsequently, multivariate regression analysis of the 2 factors showed that multiple metastatic tumors ( $p=$ 0.035 ; hazard ratio $[\mathrm{HR}]=1.6$ ) was the sole independent risk factor affecting CRC recurrence in era 1 . In era 2,4 factors, including the patient's gender, type of hepatic metastases, number of metastatic tumors, and width of negative resection margin, were identified by univariate analysis. Multivariate regression analysis of these factors indicated that multiple metastatic tumors $(p=0.017$; $\mathrm{HR}=1.6)$ and resection margin $<0.5 \mathrm{~cm}(p=0.011 ; \mathrm{HR}=$ 1.7) significantly influenced the recurrence of CRC in era 2. Further analysis of the clinical prognostic factors for all patients showed that the presence of multiple metastatic tumors and synchronous metastases were independent risk factors affecting CRC recurrence (Table 3 ).

\section{Outcomes after LR of hepatic metastasis}

Overall, the 3-, 5-, and 10-year RFS rates were $24.0 \%$, $21.1 \%$, and $19.5 \%$, respectively, and the 3-, 5-, and 10-year OS rates were $41.3 \%, 32.1 \%$, and $23.4 \%$, respectively (Figure 1). Upon further analyses of the survival rates of patients who received LR for hepatic metastasis according

Table 2 Univariate and multivariate analyses of clinicopathological factors affecting CRC recurrence of patients after liver resection for hepatic metastases in different eras.

\begin{tabular}{|c|c|c|c|c|c|c|c|c|}
\hline \multirow[t]{3}{*}{ Factors } & \multicolumn{4}{|c|}{ Era 1} & \multicolumn{4}{|c|}{ Era 2} \\
\hline & \multicolumn{3}{|c|}{ Univariate } & \multirow{2}{*}{$\begin{array}{c}\text { Multivariate } \\
p \text { value }\end{array}$} & \multicolumn{3}{|c|}{ Univariate } & \multirow{2}{*}{$\begin{array}{c}\text { Multivariate } \\
p \text { value }\end{array}$} \\
\hline & $n$ & Medium RFS months $(95 \% \mathrm{Cl})$ & $p$ value & & $n$ & Medium RFS months $(95 \% \mathrm{Cl})$ & $p$ value & \\
\hline \multicolumn{9}{|l|}{$\overline{\text { Age (years) }}$} \\
\hline$<65$ & 89 & $8.0(6.9-9.0)$ & 0.296 & - & 84 & $12.0(8.3-15.7)$ & 0.300 & - \\
\hline$\geq 65$ & 39 & $12.0(9.7-14.3)$ & & & 67 & $21.0(16.4-25.7)$ & & \\
\hline \multicolumn{9}{|l|}{ Gender } \\
\hline Female & 52 & $10.0(8.1-11.9)$ & 0.274 & - & 50 & $24.4(11.7-37.1)$ & 0.014 & 0.218 \\
\hline Male & 76 & $9.0(7.5-10.4)$ & & & 101 & $14.5(10.1-18.9)$ & & \\
\hline \multicolumn{9}{|l|}{ Primary tumor } \\
\hline Colon & 65 & $11.0(8.9-13.0)$ & 0.116 & - & 91 & $17.5(10.4-24.6)$ & 0.961 & - \\
\hline Rectum & 63 & $8.0(6.1-9.9)$ & & & 60 & $16(6.6-25.3)$ & & \\
\hline \multicolumn{9}{|l|}{ Serum CEA (mg/dL) } \\
\hline$\leq 200$ & 83 & $11.0(8.8-13.1)$ & 0.550 & - & 115 & $17.5(11.0-24.0)$ & 0.362 & - \\
\hline$>200$ & 38 & $9.0(7.8-10.1)$ & & & 94 & $15.3(6.5-24.0)$ & & \\
\hline \multicolumn{9}{|l|}{ Metastatic type } \\
\hline Synchronous & 85 & $8.0(6.8-9.2)$ & 0.052 & 0.075 & 94 & $12.9(8.5-17.3)$ & 0.009 & 0.076 \\
\hline Metachronous & 43 & $11.0(8.8-13.1)$ & & & 57 & $21.0(7.4-34.7)$ & & \\
\hline \multicolumn{9}{|l|}{ Tumor number } \\
\hline Solitary & 97 & $10.0(8.8-11.1)$ & 0.022 & 0.035 & 84 & $22.1(16.5-27.8)$ & 0.001 & 0.028 \\
\hline Multiple & 31 & $7.0(5.3-8.7)$ & & $1.6(1.0-2.5)$ & 67 & $12.0(10.6-13.5)$ & & $1.6(1.1-2.4)$ \\
\hline \multicolumn{9}{|l|}{ Maximum tumor size } \\
\hline$<5 \mathrm{~cm}$ & 108 & $10.0(8.8-11.2)$ & 0.939 & - & 122 & $18.0(12.6-23.5)$ & 0.162 & - \\
\hline$\geq 5 \mathrm{~cm}$ & 20 & $8.0(3.1-2.9)$ & & & 29 & $11.9(6.9-16.8)$ & & \\
\hline \multicolumn{9}{|c|}{ Liver resection extent } \\
\hline$<3$ segments & 88 & $10.0(8.5-11.4)$ & 0.743 & - & 114 & $17.5(11.1-23.9)$ & 0.257 & - \\
\hline$\geq 3$ segments & 40 & $9.0(7.6-10.4)$ & & & 37 & $13.0(6.0-19.9)$ & & \\
\hline \multicolumn{9}{|c|}{ Resection margin $(\mathrm{cm})$} \\
\hline$<0.5$ & 60 & $9.0(7.5-10.4)$ & 0.773 & - & 87 & $12.0(10.3-13.7)$ & 0.001 & 0.011 \\
\hline$\geq 0.5$ & 68 & $10.0(8.0-11.9)$ & & & 64 & $23.3(16.9-29.6)$ & & $1.7(1.1-2.6)$ \\
\hline \multicolumn{9}{|l|}{ Histology grade } \\
\hline Low grade & 116 & $10.0(8.8-11.2)$ & 0.101 & - & 145 & $16.5(11.0-22.0)$ & 0.921 & - \\
\hline High grade & 12 & $5.0(2.1-7.9)$ & & & 6 & $5.3(0.0-30.4)$ & & \\
\hline
\end{tabular}

RFS, recurrence-free survival; $C R C$, colorectal cancer; $C E A$, carcinoembryonic antigen; $\mathrm{Cl}$, confidence interval 
Table 3 Univariate and multivariate analyses of clinicopathological factors affecting CRC recurrence in all patients after liver resection for hepatic metastases

\begin{tabular}{|c|c|c|c|c|}
\hline \multirow[t]{2}{*}{ Factors } & \multicolumn{3}{|c|}{ Univariate analysis } & \multirow{2}{*}{$\begin{array}{l}\text { Multivariate analysis } \\
p \text { value }(\mathrm{HR}, 95 \% \mathrm{Cl})\end{array}$} \\
\hline & $n$ & Medium RFS months $(95 \% \mathrm{Cl})$ & $p$ value & \\
\hline \multicolumn{5}{|l|}{ Age (years) } \\
\hline$<65$ & 173 & $10.0(8.4-11.6)$ & 0.103 & - \\
\hline$\geq 65$ & 106 & $16.9(9.9-24.0)$ & & \\
\hline \multicolumn{5}{|l|}{ Gender } \\
\hline Male & 177 & $12.0(7.7-16.3)$ & 0.021 & 0.134 \\
\hline Female & 102 & $11.0(9.0-13.0)$ & & \\
\hline \multicolumn{5}{|l|}{ Primary tumor } \\
\hline Colon & 156 & $12.9(8.5-17.2)$ & 0.234 & - \\
\hline Rectum & 123 & $10.0(8.5-11.5)$ & & \\
\hline \multicolumn{5}{|l|}{ Serum CEA (mg/dL) } \\
\hline$<200$ & 198 & $12.0(10.6-13.4)$ & 0.567 & - \\
\hline$\geq 200$ & 72 & $10.0(7.3-12.7)$ & & \\
\hline \multicolumn{5}{|l|}{ Metastatic type } \\
\hline Synchronous & 179 & $10.8(9.3-12.3)$ & 0.002 & 0.014 \\
\hline Metachronous & 100 & $15.0(9.1-20.9)$ & & $1.5(1.1-2.0)$ \\
\hline \multicolumn{5}{|l|}{ Tumor number } \\
\hline Solitary & 181 & $14.0(8.9-19.1)$ & 0.001 & 0.028 \\
\hline Multiple & 98 & $10.0(7.8-8.7)$ & & $1.4(1.0-1.9)$ \\
\hline \multicolumn{5}{|l|}{ Maximum tumor size } \\
\hline$<5 \mathrm{~cm}$ & 230 & $12.0(10.0-14.0)$ & 0.420 & - \\
\hline$\geq 5 \mathrm{~cm}$ & 49 & $10.0(6.9-13.1)$ & & \\
\hline \multicolumn{5}{|c|}{ Extent of liver resection } \\
\hline$<3$ segments & 202 & $12.0(9.3-14.7)$ & 0.235 & - \\
\hline$\geq 3$ segments & 77 & $10.0(7.9-12.1)$ & & \\
\hline \multicolumn{5}{|c|}{ Resection margin $(\mathrm{cm})$} \\
\hline$<0.5$ & 147 & $10.0(8.5-11.5)$ & 0.019 & 0.073 \\
\hline$\geq 0.5$ & 132 & $14.5(9.1-19.9)$ & & \\
\hline \multicolumn{5}{|l|}{ Histologic grade } \\
\hline Low grade & 261 & $12.0(9.3-14.7)$ & 0.184 & - \\
\hline high grade & 18 & $5.3(1.8-8.8)$ & & \\
\hline
\end{tabular}

RFS, recurrence free survival; $C R C$, colorectal cancer; $C E A$, carcinoembryonic antigen; $\mathrm{Cl}$, confidence interval; $\mathrm{HR}$, hazard ratio

to the era in which they occurred, we found that the outcome of patients in era 2 was significantly better than that of patients in era 1 (Figure 2). Era 2 patients had better RFS curves, and the 1-, 3-, and 5-year RFS rates were $55.6 \%, 28.2 \%$, and $26.2 \%$, respectively, with a median time of CRC recurrence of 16.5 months. The 1-, 3-, and 5-year RFS rates in era 1 patients were $35.1 \%, 19.1 \%$, and $15.6 \%$, respectively, with a median time of CRC recurrence of 10.0 months (Figure $2 \mathrm{~A} ; p=0.013$ ). The 1 -, 3 -, and 5 -year OS rates of the patients in era 2 (89.3\%, 56.5\%, and $45.2 \%$, respectively, with a median survival of 44.6 months) were better than those of patients in era $1(77.2 \%, 25.2 \%$, and $18.9 \%$, respectively, with a median survival of 19 months) (Figure 2B; $p<0.0001$ ).

\section{CRC recurrence after $L R$}

The cumulative survival rates from the time of identification of CRC recurrence after LR were further analyzed, and patients with IHR and SR had poor survival curves. Nonetheless, patients with IHR had a relatively better survival curve than patients with SR. The 3-year survival rates were $14.5 \%$ in patients with IHR and $8.9 \%$ in patients with SR (Figure 3A; $p=0.002$ ). Of the 210 patients who developed CRC recurrence after LR, 41 (19.5\%), including 24 with IHR and 17 with SR, underwent surgical resection for the recurrent tumor. Of these patients, 31 (29.5\%) had CRC recurrence in era 2 and 10 (9.5\%) had CRC recurrence in era 1 . The comparison showed that the ratio of patients who underwent surgical resection for CRC recurrence was significantly higher in era 2 than in era 1 (Table $1 ; p=0.003$ ).

The survival rates according to whether or not patients received surgical resection for recurrent CRC were further analyzed. The results demonstrated that the outcome of patients who underwent surgical resection (3- and 5-year survivals of $46.8 \%$ and $34.1 \%$, respectively) was significantly 


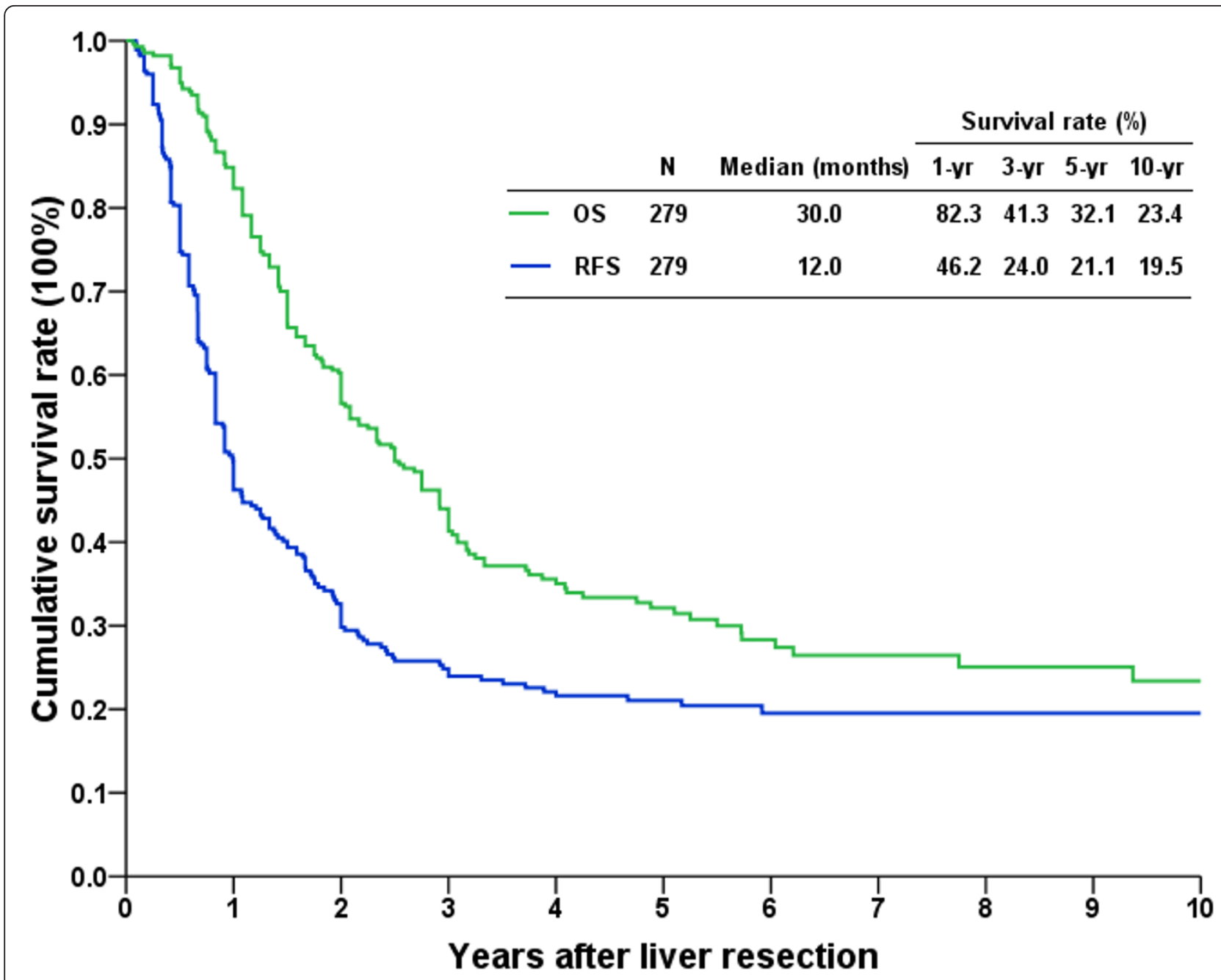

Figure 1 Long-term cumulative recurrence-free survival (RFS) and overall survival (OS) curves of patients undergoing liver resection for hepatic metastasis from colorectal cancer.

better than that of patients who had no resection (3- and 5 -year survivals of $3.3 \%$ and $2.2 \%$, respectively; Figure 3B; $p$ $<0.0001)$. The median follow-up period after surgical resection for recurrent CRC for these patients was 22.7 months (range, 4.2-107.5 months). During the follow-up period, 18 patients died of CRC relapse, 11 were still alive with cancer, and the remaining 12 were alive and cancerfree at the end of this study.

\section{Discussion}

Although CRC is a common malignancy worldwide, it has only recently been ranked as a leading cancerous disease in East Asian countries. Therefore, the concept of LR for CRC hepatic metastasis has started to receive considerable attention in East Asian countries. In this study, we have shown that the outcome of patients with CRC hepatic metastasis who have undergone LR has notably improved since 2003. The number of patients who have undergone LR for CRC hepatic metastasis has also shown a remarkable increase.

The overall recurrence incidence of $75.3 \%$ after LR for CRC hepatic metastasis found in our study is slightly higher than the recurrence rates reported by others (range, 40-74\%) [12-14]. However, our study evaluated patients treated over a 20 -year period, and treatment strategies for CRC hepatic metastasis have changed along with advances in systemic therapy. As we had selected an arbitrary break point around the year 2003 on the basis of access to modern chemotherapeutic regimens including oxaliplatin and irinotecan at our institute, both the 5-year RFS and the incidence of recurrence in era 2 were significantly better than that in era 1 . The percentage of patients who received modern chemotherapeutic regimens was significantly higher in era 2, suggesting that the use of current chemotherapy is crucial for the improvement in patient outcomes over the years. However, the regimens of 


\section{A}

B
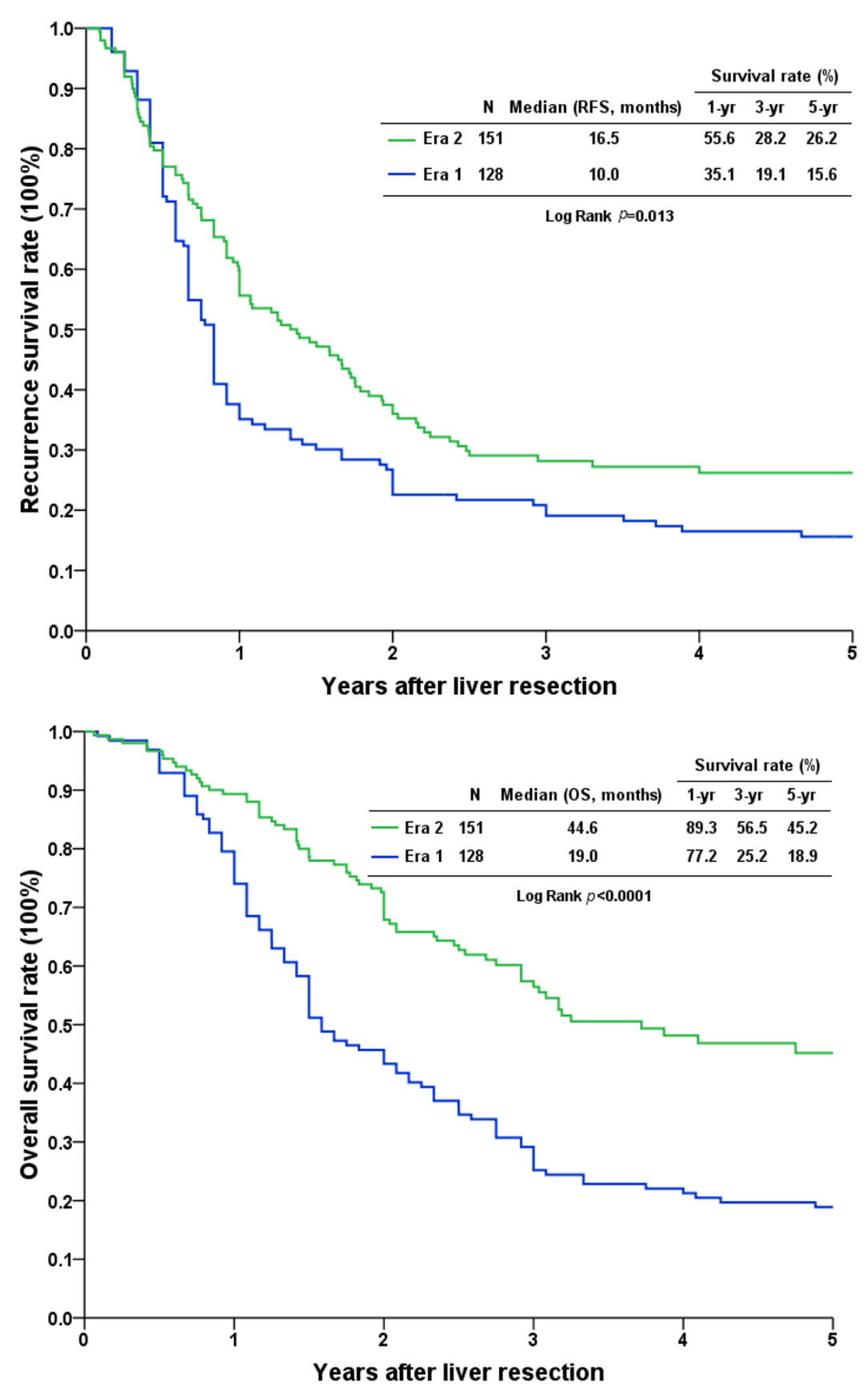

Figure 2 Cumulative survival curves of patients who underwent liver resection for hepatic metastasis according to the era of their treatment. A. The recurrence-free survival (RFS) rates in era 2 were significantly better than the RFS rates in era $1(p=0.013)$. B. The overall survival (OS) rate in era 2 was better than the OS rate in era $1(p<0.0001)$.

adjuvant chemotherapy in our patients were not identical, and comparison of patients grouped by different chemotherapeutic regimens was not practical because of the limited number of patients in each group. Therefore, further information to clarify the effect of a specific protocol in terms of postoperative adjuvant chemotherapy regimens on patient outcomes is required.

A number of previous reports have shown several prognostic factors that predict the outcome of patients undergoing LR for CRC hepatic metastasis, and similar 

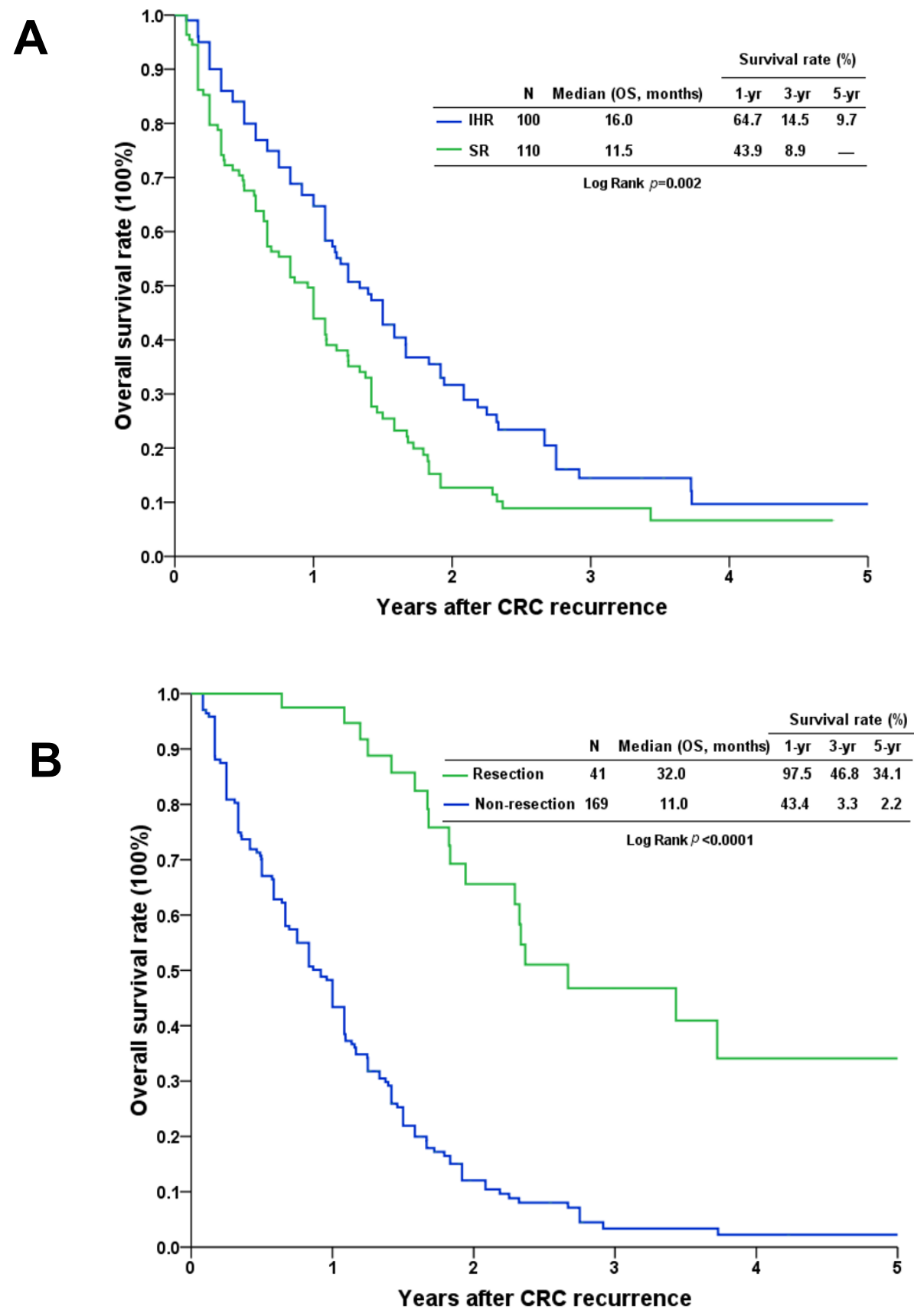

Figure 3 Kaplan-Meier cumulative survival curves of patients who underwent liver resection for hepatic metastasis after colorectal cancer recurrence. A. The survival curve of patients with intrahepatic recurrence (IHR) was relatively better than that of patients with systemic recurrence (SR) $(p=0.002)$. B. Patients who had undergone surgical resection of recurrent lesions had a better survival curve than did patients without resection $(p<0.0001)$.

factors were noted in our study $[4,9,10]$. The presence of multiple hepatic metastases is the sole prognostic factor influencing the risk of CRC recurrence in both eras, but the width of the negative resection margin appeared to be an additional risk factor during the recent era. The data generated from this analysis cannot completely explain the statistical differences. However, patients in era 2 have higher ratios of multiple hepatic metastases than those in era 1 , and it is somewhat difficult to achieve an adequate distance of negative resection 
margin during LR for such patients. In particular, to maintain an adequate remnant liver volume, limited LR or enucleation of multiple tumors might be performed, and this might lead to inadequate safe resection margins. Therefore, the width of the negative resection margin as a prognostic factor might be explained, at least in part, by aggressive LR for patients with multiple metastases in era 2. Nonetheless, the advantages and disadvantages of adequate safe resection margins remain controversial [15-18]. Despite the debate concerning the width of a negative resection margin, there is consensus that difficulty in obtaining an adequate resection margin should not be used as an exclusion criterion for LR.

The concept of managing CRC hepatic metastasis by surgical resection has greatly evolved in the last decade. For example, the traditional indications of LR for CRC hepatic metastases before the year 2000 were mainly limited to metastases confined to 1 lobe and/or less than 4 metastases,[19] which were not considered exclusion criteria for LR afterward. The advancement in surgical techniques and instruments used for LR has also decreased the perioperative morbidity and mortality, leading to a more aggressive approach of using LR for multiple hepatic metastases from CRC over time. Confidence in the utility of $L R$ is also reflected in the increased age of patients in era 2 than in era 1. Moreover, increasing evidence shows that surgical resection of metastatic lesions with curative intent has now become a standard practice for dealing with several malignancies,[20-22] and the policy has been expanded to include patients with recurrence after LR for CRC metastasis. Although it remains arguable that the prognosis of patients who are suitable to undergo surgical resection is naturally better than that of patients who are unable to undergo surgical resection, an aggressive attitude with regard to surgical resection is indeed a benefit to selected patients who have CRC hepatic metastasis or recurrent CRC from LR for hepatic metastasis. Similar to other recent studies, $[23,24]$ we also found surgical resection of isolated recurrent lesions in selected patients to be of advantage to those who have undergone LR for CRC hepatic metastasis.

\section{Conclusions}

In summary, despite the study limitation imposed by the relatively small number of patients and the retrospective nature, we showed that aggressive LR for CRC hepatic metastasis and a combination of current chemotherapeutic regimens led to improvements in the long-term outcome of such patients. However, the ultimate aim is to establish and standardize a promising treatment protocol that involves the development of novel systemic chemotherapy regimens for neoadjuvant and postoperative adjuvant treatments, combined with aggressive surgical resection to effectively prolong survival or even cure the patient of CRC hepatic metastasis.

\section{Author details}

'Department of General Surgery, Chang Gung Memorial Hospital at Linkou, Chang Gung University College of Medicine, Taoyuan, Taiwan. ${ }^{2}$ Department of Colorectal Surgery, Chang Gung Memorial Hospital at Linkou, Chang Gung University College of Medicine, Taoyuan, Taiwan.

\section{Authors' contributions}

Chan KM participated in the design of the study and drafted the manuscript. Chiang JM, Lee CF, and Yu MC participated in the acquisition of data. Lee WC, Chen JS, and Wang JY participated in the design and coordination of the study. All authors read and approved the final manuscript.

\section{Competing interests}

The authors declare that they have no competing interests.

Received: 31 August 2011 Accepted: 30 December 2011 Published: 30 December 2011

\section{References}

1. Manfredi S, Lepage C, Hatem C, Coatmeur O, Faivre J, Bouvier AM: Epidemiology and management of liver metastases from colorectal cancer. Ann Surg 2006, 244:254-259.

2. Simmonds PC, Primrose JN, Colquitt JL, Garden OJ, Poston GJ, Rees M Surgical resection of hepatic metastases from colorectal cancer: a systematic review of published studies. Br J Cancer 2006, 94:982-999.

3. Garden OJ, Rees M, Poston GJ, Mirza D, Saunders M, Ledermann J, Primrose JN, Parks RW: Guidelines for resection of colorectal cancer liver metastases. Gut 2006, 55(Suppl 3):1-8.

4. Rees M, Tekkis PP, Welsh FK, O'Rourke T, John TG: Evaluation of long-term survival after hepatic resection for metastatic colorectal cancer: a multifactorial model of 929 patients. Ann Surg 2008, 247:125-135.

5. Kato T, Yasui K, Hirai T, Kanemitsu Y, Mori T, Sugihara K, Mochizuki H, Yamamoto J: Therapeutic results for hepatic metastasis of colorectal cancer with special reference to effectiveness of hepatectomy: analysis of prognostic factors for 763 cases recorded at 18 institutions. Dis Colon Rectum 2003, 46:S22-S31.

6. Wei AC, Greig PD, Grant D, Taylor B, Langer B, Gallinger S: Survival after hepatic resection for colorectal metastases: a 10-year experience. Ann Surg Oncol 2006, 13:668-676.

7. Fernandez FG, Drebin JA, Linehan DC, Dehdashti F, Siegel BA, Strasberg SM: Five-year survival after resection of hepatic metastases from colorectal cancer in patients screened by positron emission tomography with F-18 fluorodeoxyglucose (FDG-PET). Ann Surg 2004, 240:438-447.

8. Choti MA, Sitzmann JV, Tiburi MF, Sumetchotimetha W, Rangsin R, Schulick RD, Lillemoe KD, Yeo CJ, Cameron JL: Trends in long-term survival following liver resection for hepatic colorectal metastases. Ann Surg 2002, 235:759-766

9. Fong Y, Fortner J, Sun RL, Brennan MF, Blumgart LH: Clinical score for predicting recurrence after hepatic resection for metastatic colorectal cancer: analysis of 1001 consecutive cases. Ann Surg 1999, 230:309-318.

10. Nordlinger B, Guiguet M, Vaillant JC, Balladur P, Boudjema K, Bachellier P, Jaeck D: Surgical resection of colorectal carcinoma metastases to the liver. A prognostic scoring system to improve case selection, based on 1568 patients. Association Francaise de Chirurgie. Cancer 1996, 77:1254-1262.

11. Ueno H, Mochizuki $H$, Hashiguchi $Y$, Hatsuse $K$, Fujimoto $H$, Hase K: Predictors of extrahepatic recurrence after resection of colorectal liver metastases. Br J Surg 2004, 91:327-333.

12. Bozzetti F, Doci R, Bignami P, Morabito A, Gennari L: Patterns of failure following surgical resection of colorectal cancer liver metastases. Rationale for a multimodal approach. Ann Surg 1987, 205:264-270.

13. Holm A, Bradley E, Aldrete JS: Hepatic resection of metastasis from colorectal carcinoma. Morbidity, mortality, and pattern of recurrence. Ann Surg 1989, 209:428-434. 
14. Sugihara K, Hojo K, Moriya Y, Yamasaki S, Kosuge T, Takayama T: Pattern of recurrence after hepatic resection for colorectal metastases. Br I Surg 1993, 80:1032-1035.

15. Bodingbauer M, Tamandl D, Schmid K, Plank C, Schima W, Gruenberger T: Size of surgical margin does not influence recurrence rates after curative liver resection for colorectal cancer liver metastases. $\mathrm{Br} J$ Surg 2007, 94:1133-1138.

16. Nuzzo G, Giuliante F, Ardito F, Vellone M, Giovannini I, Federico B, Vecchio FM: Influence of surgical margin on type of recurrence after liver resection for colorectal metastases: a single-center experience. Surgery 2008, 143:384-393

17. Pawlik TM, Scoggins CR, Zorzi D, Abdalla EK, Andres A, Eng C, Curley SA, Loyer EM, Muratore A, Mentha $G$, et al: Effect of surgical margin status on survival and site of recurrence after hepatic resection for colorectal metastases. Ann Surg 2005, 241:715-22, discussion.

18. Muratore A, Ribero D, Zimmitti G, Mellano A, Langella S, Capussotti L: Resection margin and recurrence-free survival after liver resection of colorectal metastases. Ann Surg Oncol 2010, 17:1324-1329.

19. Rees $M$, Plant $G$, Bygrave $S$ : Late results justify resection for multiple hepatic metastases from colorectal cancer. Br J Surg 1997, 84:1136-1140.

20. Fourquier P, Regnard JF, Rea S, Levi JF, Levasseur P: Lung metastases of renal cell carcinoma: results of surgical resection. Eur J Cardiothorac Surg 1997, 11:17-21.

21. van Geel AN, Pastorino U, Jauch KW, Judson IR, van CF, Buesa JM, Nielsen OS, Boudinet A, Tursz T, Schmitz PI: Surgical treatment of lung metastases: The European Organization for Research and Treatment of Cancer-Soft Tissue and Bone Sarcoma Group study of 255 patients. Cancer 1996, 77:675-682.

22. Ollila DW: Complete metastasectomy in patients with stage IV metastatic melanoma. Lancet Oncol 2006, 7:919-924.

23. Petrowsky $H$, Gonen $M$, Jarnagin $W$, Lorenz $M$, DeMatteo $R$, Heinrich $S$, Encke A, Blumgart L, Fong Y: Second liver resections are safe and effective treatment for recurrent hepatic metastases from colorectal cancer: a bi-institutional analysis. Ann Surg 2002, 235:863-871.

24. Adam R, Bismuth H, Castaing D, Waechter F, Navarro F, Abascal A, Majno P, Engerran L: Repeat hepatectomy for colorectal liver metastases. Ann Surg 1997, 225:51-60.

doi:10.1186/1477-7819-9-174

Cite this article as: Chan et al:: Outcomes of resection for colorectal cancer hepatic metastases stratified by evolving eras of treatment. World Journal of Surgical Oncology 2011 9:174.

\section{Submit your next manuscript to BioMed Central and take full advantage of:}

- Convenient online submission

- Thorough peer review

- No space constraints or color figure charges

- Immediate publication on acceptance

- Inclusion in PubMed, CAS, Scopus and Google Scholar

- Research which is freely available for redistribution

Submit your manuscript at www.biomedcentral.com/submit
Biomed Central 